\title{
Toxicological Assessment of Betulin Entrapped in a Polyurethane Carrier
}

\begin{abstract}
FLORIN BORCAN², CODRUTA M. SOICA ${ }^{1}$, VOICHITA LAZUREANU2*, IULIA A. PINZARU1', ADELINA CHEVERESAN²", MARIOARA POENARU ${ }^{2}$

${ }^{1}$ Victor Babes University of Medicine and Pharmacy Timisoara, Faculty of Pharmacy, $2^{\text {nd }}$ Eftimie Murgu Sq., 300041, Timisoara, Romania

Victor Babes University of Medicine and Pharmacy Timisoara, Faculty of Medicine, $2^{\text {nd }}$ Eftimie Murgu Sq., 300041, Timisoara, Romania

Natural mixtures based on bioflavonoids, terpenoids, glycosidic compounds, polyphenols, anthocyanins and essential fatty acids are often more effective and non-toxic than many synthetic drugs. Betulin, a terpene compound with many key-roles in alternative medicine, is almost insoluble in water due to its pentacyclic structure. Different drug carriers are developed to improve the drug efficacy and release. This paper described the evolution of some skin parameters (transepidermal water loss, erythema and stratum corneum hydration) after a short and respectively a long exposure to a polyurethane carrier with and without betulin using sodium lauryl sulfate as reference. It was found that these compounds are safe for human use and the hydratant effect of betulin was reconfirmed.
\end{abstract}

Keywords: corneometry, drug delivery system, mexametry, TEWA, triterpenoids, Zeta potential

Natural products have been used in oriental medicine for thousands of years and they have an important role in the discovery of new drugs [1]. Triterpenes are metabolites found in many plants and they are synthesized during the squalene cyclization; the tetracyclic and pentacyclic triterpenes are the most numerous. Pentacyclic triterpenes are found in considerable quantities in birch (in leaves or in bark). Triterpenoids have been shown to have important actions in many diseases: anti-inflammatory activity, antitumoral agent, antibacterial and antiviral potential [2, 3].

Betulin, a triterpenoid with lupan skeleton ( fig. 1), can be isolated from the bark of white birch (Betula spp.), and it is approx. $30 \%$ of the dry weight. C.M. Soica and her team described that pure betulin presents an insufficient aqueous solubility to prepare therapeutic products; this is the reason why many research groups developed different drug delivery systems used as a betulin carrier which can improve its solubilitv in water [41.

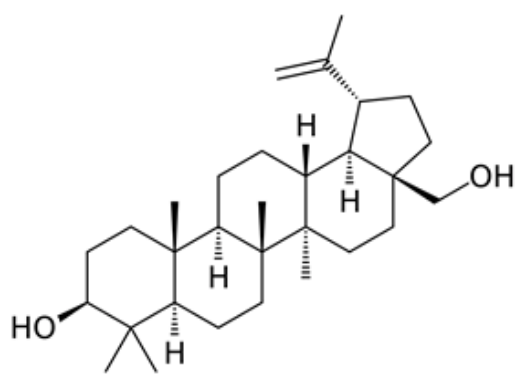

Fig. 1. The chemical structure of betulin

Polyurethane materials are widely used as foams, coating and adhesives in building and insulating industry, as artificial membranes, catheters, vascular grafts and heart valves in biomedical applications [5]. Polyurethanes nanocapsules were synthesized and they were used as drug delivery systems in the last decade. Polyurethane nanoparticles (PuNp) are very easy and cheap to synthesize and to adjust in their size and properties: the stirring speed during synthesis and the amount of chain extenders (diols or diamines with low molecular weight) can modify the structures' size, while the polyester/polyether ratio can adjust the drug release rate [6].
The toxicity of different PuNp was already evaluate by our team using animal models [7-8]. The main aim of this research was to evaluate the toxicity of polyurethane particles with and without betulin by assess the human skin irritation potential using non-invasive techniques.

\section{Experimental part}

Reagents

The following reagents were used to synthesize PuNp without any previous purification: lysine diisocyanate ester, LDI (Hangzhou Imaginechem Co., China), butanediol, BD (Carl Roth GmbH, Germany), betulin (Sigma-Aldrich, USA), polyethylene glycol (PEG), Tween ${ }^{\circledR} 20$ and acetone (Merck, Germany).

\section{Synthesis procedure}

The synthesis is based on a polyaddition reaction between a polyol and a diisocyanate during the following steps: 1. preparation of the organic phase (LDI is mixed with acetone $1: 24 \mathrm{v} / \mathrm{v}$ and heated at $40^{\circ} \mathrm{C}$ ); 2. preparation of the aqueous phase (BD, PEG and distilled water were mixed $1: 2.5: 34 \mathrm{v} / \mathrm{v} / \mathrm{v}$ and heated at $40^{\circ} \mathrm{C}$ ); 3 . the two phase were mixed at $40^{\circ} \mathrm{C}$ for four hours; 4 . the solvent and a part of water were removed by keeping the obtained suspensions in Petri dishes at room temperature until no mass change was observed; 5 . the products were purified by multiple cycles of centrifugation - redispersion in a mixture of water-acetone 1:1 (v/v). The procedure was repeated two times in order to obtain empty PuNp (sample 0) and PuNp with betulin (sample 1).

\section{Physical and chemical characterization}

The PuNp size and surface charge were measured using a Zetasizer Analyser (Cordouan Technol., France) at $25^{\circ} \mathrm{C}$, with around $10 \mu \mathrm{s}$ as time interval and number of channels between 650 and 800 , laser power approx. 80\%, a continuous acquisition mode and analysis mode (PadeLaplace) as parameters of Size Analyzer and medium resolution and Henry function (Smoluchowski) as parameters of Zeta Potential Analyzer. 


\section{Study on the human skin}

24 healthy volunteers ( 17 women and 7 men, between 21 and 33 years old) were enrolled in this research. They participated to a short ( 6 days) and a long (1 month) evaluation of skin parameters such as transepidermalwater loss (TEWA), erythema and skin hydration. The parameters were assessed using new and non-invasive techniques based on skin probes (Tewameter ${ }^{\circledR} \mathrm{TM} 300$, Mexameter ${ }^{\circledR} \mathrm{MX} 18$, Corneometer ${ }^{\circledR} \mathrm{CM}$ 825) connected to a Multi Probe Adapter (MPA) from Courage-Khazaka, Germany. Three different areas were marked on the left forearm of every subject; $0.5 \mathrm{~mL}$ of sample 0 , sample 1 , respectively sodium lauryl sulfate $1 \%$ (SLS) were applied in these areas daily in the first 6 days and once a week in the nextthree weeks. Skin parameters were comparatively monitored at 15 min after every application: all data are expressed as differences between the parameter level after vs. before the application due to the wide range of values measured for all subjects.

The investigations were done according to the declaration of Helsinki principles. Authors declare that all procedures respect the specific regulations and standards: this study was firstly evaluated and approved by the Ethical Committee of Victor Babes University of Medicine and Pharmacy Timisoara, Romania. Prior to subjects' participation in this research, written informed consent forms were signed; all human volunteers were agreed with the publications of the study results.

\section{Statistics}

Statistical data were obtained using IBM SPSS. All measurements were done in triplicate and the results are average values \pm standard error. One-way ANOVA and Bonferonni-Dunn tests were used to determine statistical differences; $* *$ and $* * *$ indicate $p<0.01$ and $p<0.001$.

\section{Results and discussions}

Our team already obtained similar polyurethane nanoand micro-structures in other several studies. They present a good thermal stability between 30 and $300^{\circ} \mathrm{C}$ and a good encapsulation efficacy (around 70\%). The evaluation of their aspect often revealed the formation of particles' clusters probably due to the decreased amount of surfactant that was used in the synthesis [9-13].

Toxicological evaluations of these drug delivery systems were done by our research team using animal models in previous years. The skin of hairless mice, more sensitive than the human one, was selected for the assessment of skin parameters in the past and the results indicate the safe use for humans.

Table 1 presents the results of Zetasizer analysis. The obtaining of polyurethane particles with a diameter between nano- and micro-scale is indicated and it is important to mention that only one particles' population was obtained with a low polydispersity index. The Zeta potential values indicate the formation of agglomerations, which appear in many colloidal solutions.

The increase of transepidermal-water loss reveals a skin injury or the presence of an aggressive chemical agent; thus, this parameter can be used to evaluate the irritation potential of a new synthesized compound.

Figure 2 presents similar increases during the first 6 days, but it is important to observe the level of TEWA difference: around 4 units for the SLS 1\% solution, while PuNp samples present around 3 units (just 75\%). Some increases of these parameters are normal if their level is low. The values are still increased after the first week, but the results of the long exposure (fig. 2b) indicate lower increases.

The increases of TEWA values are always accompanied by the increases of erythema and decreases of stratum corneum moisture.
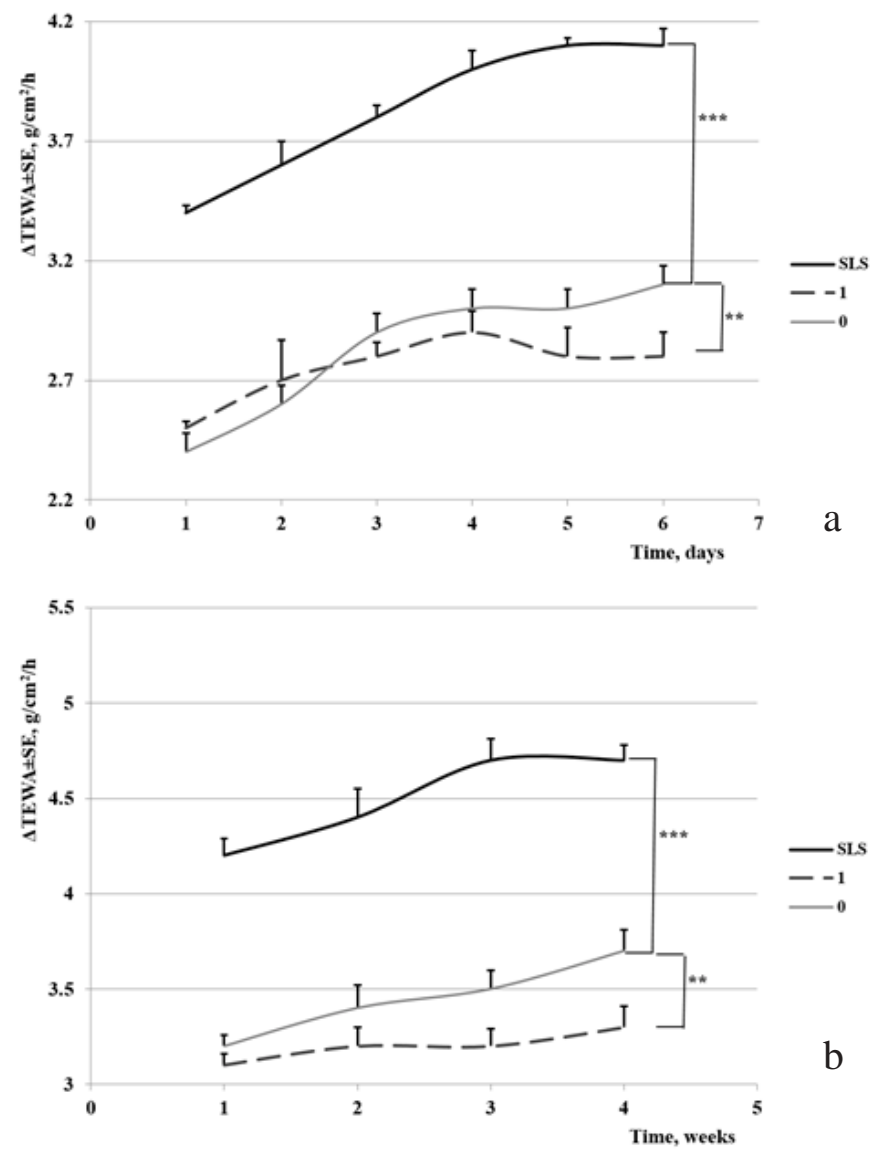

Fig. 2.a,b. The evolution of transepidermal water loss during (a) a short exposure and (b) a prolonged exposure

Erythema, the skin redness, can be temporary for just a few moments or can be present for several days, weeks or months in a row. It can be caused by skin infections and/or disorders, by inflammatory or allergic conditions as well as emotional, environmental or food factors. Some causes of erythema can be avoided, others not.

Figure 3 shows erythema increases more accentuated in the first six days than those recorded in the case of prolonged exposure. However, these increases are normal for a skin exposed to a experiment; it can be seen that PuNp samples give lower modifications than SLS solution used as reference.

One of the main characteristics of creams based on pentacyclic triterpenes is their hydratant potential [14]. This

\begin{tabular}{|c|c|c|c|}
\hline \multirow{2}{*}{ Sample name } & \multicolumn{2}{|c|}{ Particle size (nm) } & Zeta Potential (mV) \\
\cline { 2 - 3 } & Mean \pm SD & Polydispersity index & Mean \pm SD \\
\hline Sample 0 & $104 \pm 9$ & 0.3 & $+21.5 \pm 4.6$ \\
\hline Sample 1 & $118 \pm 14$ & 0.4 & $+16.7 \pm 5.2$ \\
\hline
\end{tabular}

Table 1

THE ZETASIZER CHARACTERIZATION 

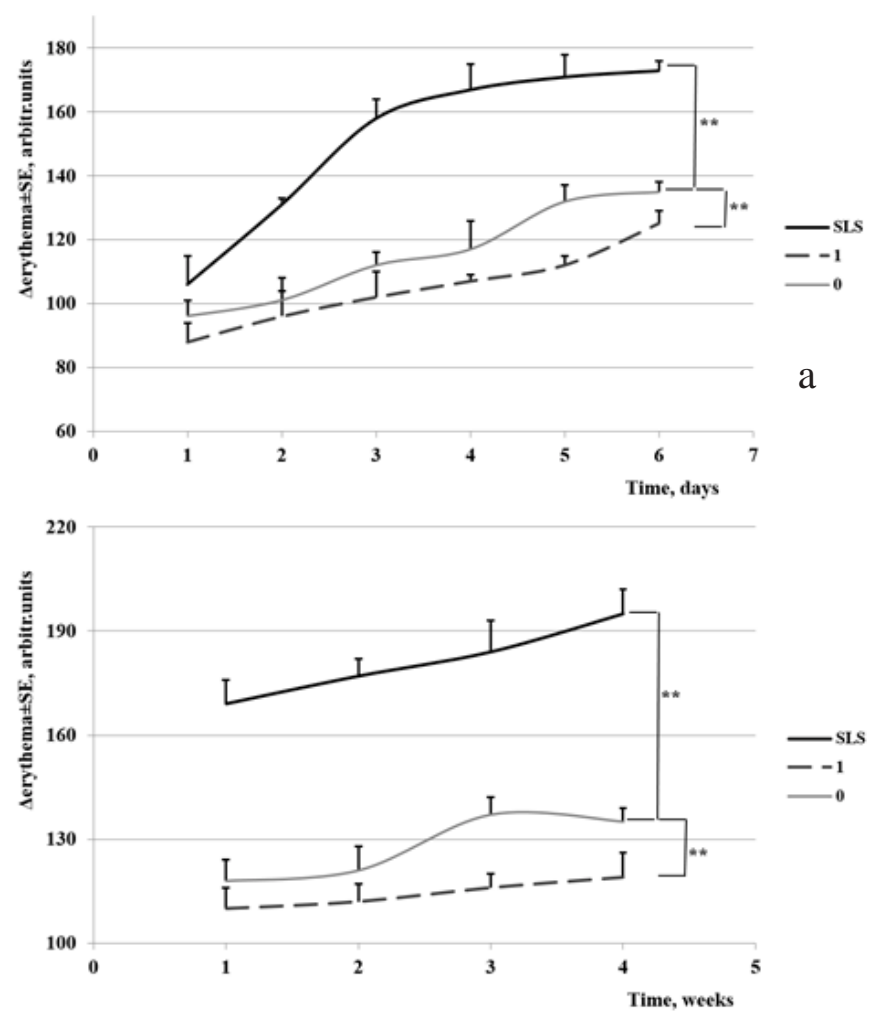

Fig. 3. The evolution of erythema during

(a) a short exposure and (b) a prolonged exposure

aspect can be observed in figure 4 . The sample 1 containing PuNp with betulin is the only one case where the hydration level did not decreased; on the other hand, an important decrease was recorded for the SLS solution, a normal one for sample based on empty PuNp in the first six days.
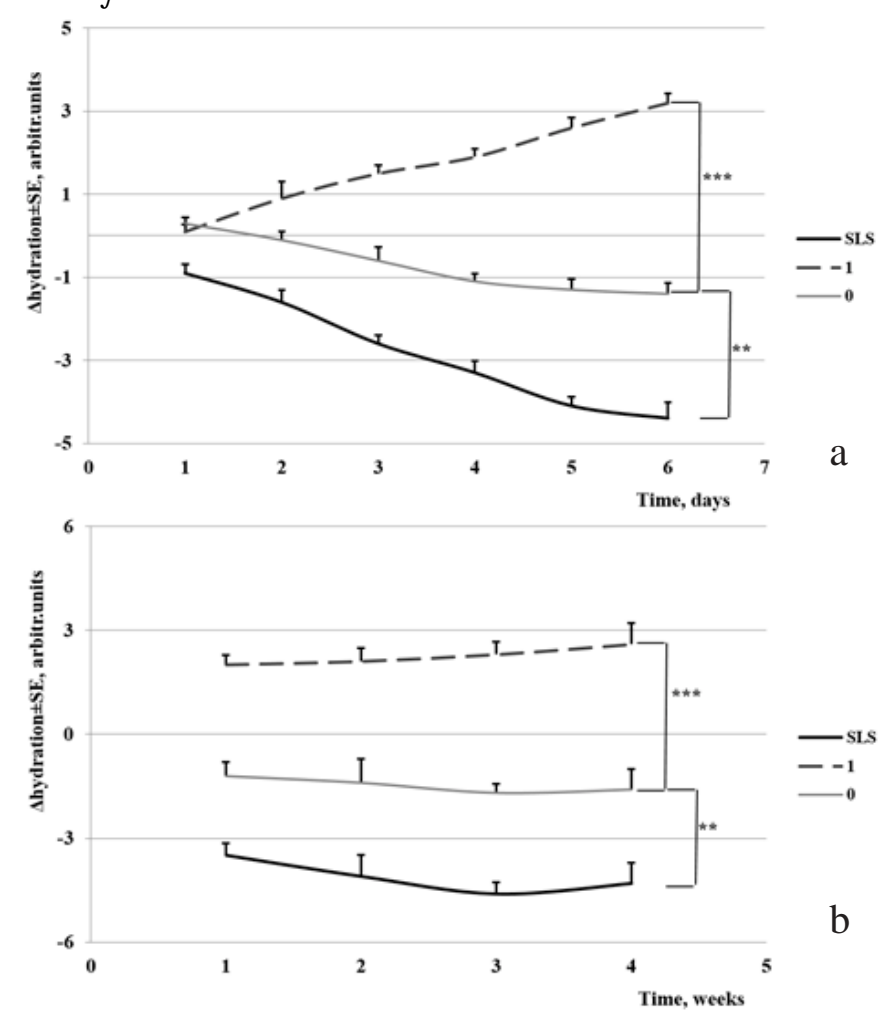

Fig. 4. The evolution of skin hydration during

(a) a short exposure and (b) a prolonged exposure

Sodium lauryl sulfate (SLS) or sodium dodecyl sulfate is a highly effective surfactant with a well-known irritant potential; this is the reason why it is used as control in many dermatological assays [15]. Its irritant effects appear at very low concentrations (between 0.2 and $0.5 \%$ ); however, it is still use and the concentrations interval is up to $5 \%$. M.F. Islam used SLS to disperse or suspend carbon nanotubes [16]. We used SLS 1\% solution as reference compound and the modifications of transepidermal-water loss, erythema and skin hydration were obvious (figs. 2-4).

\section{Conclusions}

Betulin is a natural compound, very abundant in the bark of birch tree. The present study presents the obtaining of a polymer drug delivery system used to improve betulin aqueous solubility and obtained by an interfacial polyaddition technique combined with spontaneous emulsification; on the other hand, a toxicological assessment of this carrier was done using new and noninvasive techniques: human skin was exposed for a short period ( 6 days) and a prolonged one ( 1 month) to these compounds. The changes of transepidermal water loss, erythema and skin hydration values in the case of polyurethane carrier were compared with those obtained on a skin area treated with a SLS solution used as reference. The good results indicate that these products are safe to use on human skin.

Acknowledgements: This work was supported by the CNCS-UEFISCDI, projectPN-III-P2-2.1-BG-2016-0354.

\section{References}

1. YANG, L., YANG, C., LI, C., ZHAO, Q., LIU, L., FANG, X., Chen, X.Y., Sci. Bull. (Beijing), 61, 2016, p. 3.

2. BEBENEK, E., KADELA-TOMANEK, M., CHROBAK, E., WIETRZYK, J., SADOWSKA, J., BORYCZKA, S., Med. Chem. Res., 26, 2017, p. 1.

3. Cl, X., ZHOU, J., LV, H., YU, Q., PENG, L., HUA, S., Cell Death Dis., 8, 2017, e2798.

4. SOICA, C.M., PEEV, C.I., CIURLEA, S., AMBRUS, R., DEHELEAN, C., Farmacia, 58, 2012, p. 611.

5. JOSEPH, J., PATEL, R.M., WENHAM, A., SMITH, J.R., Transactions of the IMF, 96, 2018, p. 121.

6. MUNTEANU, M.F., ARDELEAN, A., BORCAN, F., TRIFUNSCHI, S.I., GLIGOR, R., ARDELEAN, S.A., CORICOVAC, D., PINZARU, I., ANDRICA, F., BORCAN, L.-C., Curr. Drug Deliv., 14, 2017, p. 1178.

7. POPA, Z., RUSU, L.C., SUSAN, R., PINZARU, I., ARDELEAN, E., BORCAN, F., VOICU, M., TUTA SAS, I., POPOVICI, R.A., LAZUREANU, V., Mat.. Plast., 55, no. 1, 2018, p. 9.

8. SUSAN, R., PANA, R., TUTA SAS, I., BORCAN, F., ARDELEAN, E., ENACHE, A., PINZARU, I., Mat. Plast., 55, no. 1, 2018, p. 91.

9. BORCAN, F., SOICA, C.M., DEHELEAN, C.A., GANTA, S., AMIJI, M.M., Rev. Chim. (Bucharest), 63, 2012, no. 11, p. 1164.

10. HEGHES, A., SOICA, C.M., ARDELEAN, S., AMBRUS, R., MUNTEAN, D., GALUSCAN, A., DRAGOS, D., IONESCU, D., BORCAN, F., Chem. Cent. J., 7, 2013, p. 1.

11. CITU, I.M., TOMA, C., TRANDAFIRESCU, C., ANTAL, D., ZAMBORI, C., OPREAN, C., BOJIN, F., BORCAN, F., PAUNESCU, V., LAZUREANU, V., Rev. Chim. (Bucharest), 66, no. 3, 2015, p. 431.

12. DANCIU, C., BORCAN, F., SOICA, C., ZUPKO, I., CSANYI, E., AMBRUS, R., MUNTEAN, D., SASS, C., ANTAL, D., TOMA, C., DEHELEAN, C., Nat. Prod. Comm., 10, 2015, p. 951.

13. TRANDAFIRESCU, C., LEDETI, I., CORICOVAC, D.E., SOICA, C.M., PINZARU, I., DEHELEAN, C.A., IACOB, R.E., BORCAN, F., Mat. Plast., 53, no. 2, 2016, p. 205.

14. CINTA-PINZARU, S., DEHELEAN, C.A., SOICA, C., CULEA, M., BORCAN, F., Chem. Cent. J., 6, 2012, p. 1.

15. HORITA, K., HORITA, D., TOMITA, H., YASOSHIMA, M., YAGAMI, A., MATSUNAGA, K., Toxicology, 382, 2017, p. 10.

16. ISLAM, M.F., Nano Letters, 3, 2003, p. 269.

Manuscript received: 15. 01.2018 